\title{
Commentary: Octopamine Drives Endurance Exercise Adaptations in Drosophila
}

\author{
Kristin A Richardson', Robert J Wessells ${ }^{1 *}$ \\ 'Department of Physiology, Wayne State School of Medicine, Detroit, MI 48201, USA
}

\section{Article Info}

\section{Article Notes}

Received: September 14, 2018

Accepted: October 16, 2018

\section{${ }^{*}$ Correspondence:}

Dr. RJ Wessells, Assistant Professor, Department of Physiology, Wayne State School of Medicine, Detroit, MI 48221, USA:

E-mail: rwessell@med.wayne.edu.

(c) 2018 Wessells RJ. This article is distributed under the terms of the Creative Commons Attribution 4.0 International License

\section{Introduction}

Endurance exercise is an effective therapeutic tool for promoting healthy brain, skeletal muscle, and cardiovascular function. It can also be valuable in the prevention of metabolic and cardiovascular diseases ${ }^{1}$. Although much work has been done to elucidate the molecular mechanisms of exercise, our understanding of these mechanisms in humans and animals is still incomplete. In order to bring the power of invertebrate genetics to bear on this topic, Piazza et al. have developed a novel instrument to carry out exercise training in Drosophila known as the Power Tower ${ }^{2}$. Drosophila melanogaster is an excellent model for studying genetic factors mediating the physiological response to endurance exercise. Due to their short lifespan and ease of genetic manipulation, they allow for large, rapid experiments that are easily repeatable. By utilizing the instinctive negative geotaxis behavior of Drosophila, the Power Tower repeatedly raises and drops several trays of fly vials to induce climbing. Induction of climbing in a controlled three-week daily protocol causes exercise training to occur ${ }^{3}$. Training consistently increases parameters such as climbing speed, cardiac performance, lipolysis, and endurance ${ }^{2,4}$. Exercise training in Drosophila also increases mitochondrial activity and turnover, as well as gene expression of genes related to fatty acid oxidation ${ }^{2,5,6}$.

Using this model, Sujkowski et al. recently discovered that the activity of octopaminergic neurons is required for exercise adaptations to occur, and that activation of these neurons is sufficient to fully mimic the effects of exercise, even in enforced sedentary populations ${ }^{7}$. In Drosophila, octopamine (OA) plays many diverse roles in shaping behavioral and physiological processes ${ }^{8}$. This biogenic amine is produced in certain invertebrate neurons and is well known for its involvement in insect behaviors ${ }^{8}$. Intermittent or continuous depolarization of octopaminergic neurons, causing release of $\mathrm{OA}$, leads to increases in climbing speed, flight performance, endurance, cardiac pacing and lipolysis ${ }^{7}$, even in sedentary flies. Feeding $\mathrm{OA}$ to sedentary flies also causes unexercised cohorts to resemble trained flies in climbing speed, endurance, and flight performance ${ }^{7}$. Additionally, flies treated with OA gain no further improvement from exercise training, consistent with the idea that $\mathrm{OA}$ and exercise act in the same pathway. Blocking OA transport and release prevents improvements in performance after training ${ }^{7}$, supporting the idea that $\mathrm{OA}$ is required for exercise adaptations to take place. In the fly, there are at least four adrenergic-like receptors that exist in brain and muscle tissue for $\mathrm{OA}$, and they are required for different aspects of exercise adaptation ${ }^{7}$. One particular receptor, the octopamine $\beta$-adrenergic-like receptor $0 \operatorname{ct} \beta 2 \mathrm{R}$, seems to be the most broadly required for preserving the entire exercise response ${ }^{7}$. 
Could Norepinephrine Drive Exercise Adaptation in Vertebrates?

Although abundant in invertebrates, $\mathrm{OA}$ is found in only trace amounts in vertebrate systems and has no known physiological significance there ${ }^{9}$. However, the octopaminergic system of invertebrates is functionally replaced by the noradrenergic system in vertebrate species ${ }^{9}$. Norepinephrine (NE), the vertebrate counterpart of $\mathrm{OA}$, has many functions in common with $\mathrm{OA}^{8,9}$, including the stimulation of glycogenolysis ${ }^{9}$, increases in muscle contractility ${ }^{9}$, and alterations in muscle and fat body metabolism ${ }^{9}$. Both OA and NE are stress hormones, derived from the amino acid tyrosine, that have been shown to be released in increased quantities during periods of stress or high energy demand ${ }^{10,11}$, such as during endurance exercise, and are implicated in the "fight-or-flight" response of their respective organisms. In addition, both octopaminergic and noradrenergic signaling occur through binding to adrenergic g-protein coupled receptors, resulting in the activation of signaling pathways such as the PKA/cAMP pathway, and triggering alterations in physiological functions and behaviors of the organism, including increases in arousal and muscle contractility.

One area not addressed in the original article is the pathway through which OA delivers its beneficial effects following exercise. The signaling cascades triggered by $\mathrm{OA}$ in response to exercise have not been well described, but $\mathrm{OA}$ is known to work in a PKA/cAMP dependent manner to promote arousal ${ }^{12,13}$. There is also some evidence that $\mathrm{OA}$ can cause increases in intracellular calcium concentrations through interactions with the PKC pathway ${ }^{9,14}$, which could be relevant to changes in muscle contractility following exercise. Increases in OA concentrations have been shown to activate phospholipase C, leading to an increase in IP-3 levels and stimulating intracellular calcium release $\mathrm{e}^{14}$. This increase in intracellular calcium concentration in response to $\mathrm{OA}$ could provide increased availability of calcium ions to bind troponin and aid in muscle contraction.

Like OA, NE release is increased during situations of stress or high energy demand in order to prepare the body for action. Endurance exercise results in the activation of the sympathetic nervous system, stimulating the release of $\mathrm{NE}$, with greater intensity training resulting in a larger response ${ }^{15-17}$. This is comparable to what has been seen with $\mathrm{OA}$ in insects following acute shifts in arousal state, where the amount of $\mathrm{OA}$ released reflects the level of arousal, i.e. more is released with larger increases in the need for activity ${ }^{11}$.

During a bout of exercise, the activity of the sympathetic nervous system increases, and NE starts to be released in increasing quantities ${ }^{15-18}$. Once released, the NE molecules bind adrenergic receptors on the blood vessels and the heart causing an increase in blood pressure and heart rate. These increases in both blood pressure and heart rate are necessary to deliver oxygenated blood to the working muscles. These processes downstream of sympathetic activation may be required for successful exercise, as the use of drugs such as $\beta$-blockers has been seen to impair exercise capacity ${ }^{19-21}$. Trained runners treated with $\beta$-blockers saw significant increases in the time it took to run $10-\mathrm{km}$ races $^{19}$. They also had significant reductions in maximal heart rate and the amount of oxygen each individual could utilize during exercise $\left(\mathrm{VO}_{2} \max \right)^{19}$. The use of $\beta$-blockers also results in a decrease in maximal exercise power ${ }^{20}$ and exercise capacity ${ }^{21}$. Furthermore, the discontinuation of $\beta$-blockers results in increased 6-minute walking distances, cardiac output, and exercise capacity ${ }^{22}$. Taken together, it seems that the action of $\beta$-blockers hinders exercise ability acutely. While the study subjects had variable disease states, which could confound the results, these studies provide supporting evidence that adrenergic signaling is important for exercise performance in humans, as it is in flies. More work is necessary to assess the potential long-term effects of NE or adrenergic activity on adaptation to chronic exercise.

\section{Using Sensory Stimuli to Elicit an Exercise Response in Humans}

For years, researchers have been looking into the possibility of using sensory stimuli to elicit an exercise response in individuals that are incapable of physical activity. A few examples of therapies that have been used to improve or maintain healthy function in a variety of different conditions are functional electrical stimulation (FES), neuromuscular electrical stimulation (NMES), and vibration therapy.

FES and NMES both involve electrical stimulation of skeletal muscle as a means to improve function. In paraand quadriplegic spinal cord injury patients, FES has been shown to improve muscular and cardiovascular fitness by inducing cyclic contractions in paralyzed muscle ${ }^{23}$. FESinduced lower-limb muscle contraction therapy programs result in metabolic and cardiorespiratory responses similar to those seen in healthy individuals following periods of low-intensity exercise by delivering periodic electrical pulses to the muscle ${ }^{23}$. Overtime, this FES stimulation may lead to improved cardiovascular fitness, owing to the decrease in both resting heart rate and blood pressure, and the increase in stroke volume and cardiac output seen during FES-induced exercise ${ }^{23}$. This type of therapy may also alleviate hypotension due to poor venous return and increase muscle performance ${ }^{23}$. NMES has been exploited in cases of neuromuscular damage, where it has been shown to be effective in improving muscle strength and blood flow while also decreasing atrophy ${ }^{24}$. 
In contrast to using electrical currents, whole-body vibration therapy uses periodic, low-frequency mechanical signals to enhance athletic performance. Vibration therapy has been implemented as a sensory stimulus to promote balance and leg muscle strength in the elderly ${ }^{25}$, and to increase bone and muscle mass in patients with low bone mineral density following 12-months with 10-minutes/day of standing on a vibrating platform ${ }^{26}$.

While these examples of induced passive exercise provide some evidence that external sensory stimuli can give benefits similar to exercise, it is important to point out that in one way or another they all involve stimulation of muscle contraction. Indeed, some benefits of exercise, especially those involving muscle hypertrophy, do require actual muscle contraction, or even load bearing muscle contraction ${ }^{27-29}$. The potential benefits of sensory stimulation of molecular pathways downstream of exercise without muscle contraction are still largely unexplored in human subjects. In Drosophila, there are substantial benefits to performance in periodically OA-stimulated animals, even under restrained conditions, suggesting that it may be possible to provide some benefits of exercise independent of muscle contraction ${ }^{7}$. It remains to be seen how many of the benefits we see in flies could translate to humans. For instance, stimulation of adrenergic signaling may not completely prevent atrophy of skeletal muscle in disabled or bed-ridden patients, but it may nevertheless provide other important benefits to metabolic health. If this were true, an inexpensive way to prevent metabolic consequences of enforced sedentary lifestyles would be of substantial impact to disabled patients or patients on extended bedrest.

Because regular, periodic stimulation of octopaminergic neurons was sufficient to deliver the benefits of exercise to sedentary Drosophila without the need for actual physical activity ${ }^{7}$, we speculate that it may be possible to generate salutary effects by periodic stimulation of NE secretion in humans. The original article briefly introduces this idea of transitioning from invertebrates to vertebrates using periodic stimulation of endogenous NE release. While continuous activation of this "fight-or-flight" state would lead to chronic pathological conditions such as hypertension, transient activation of this response, as with exercise, is thought to be protective by conferring a resilience to stress ${ }^{30-33}$.

One potential method of periodic stimulation of the noradrenergic system using sensory inputs could be the use of virtual reality (VR) technology to simulate the experience of exercise. It is possible that VR could act as a sensory stimulus for the activation of the stress response, causing an increase in NE release that could potentially generate some of the same responses that exercise generates in the absence of actual physical activity. It is possible that repeated application of such a stimulus could mimic a subset of the effects of chronic exercise and provide substantial metabolic benefits to sedentary humans, such as improved insulin sensitivity, lipid metabolism, and mitochondrial health (Figure 1). If this is the case, it would constitute a non-invasive means of therapeutic intervention in cases of restricted mobility and promote long-term health for individuals unable to carry out physical exercise. VR could be a valuable therapeutic tool for elderly individuals who have difficulty with mobility or are easily injured. Someone who is at high-risk for falls, for example, could use a VR helmet to engage in stationary virtual exercise, providing some of the metabolic benefits of exercise while eliminating the risk of broken bones due to falls while running or biking. If it can be successfully developed and optimized, this technology would be an inexpensive and safe option for patients on extended bed rest due to injury or illness. As declines in metabolic health are a major problem associated with long-term immobilization ${ }^{34-36}$, amelioration of such effects would have a major impact on health care.

\section{Conclusion}

The Drosophila exercise model provides a useful way of looking at the mechanisms that contribute to individual responses to exercise and can be used in parallel with valuable exercise studies in other genetics models, such as C. elegans ${ }^{37}$. Invertebrate models are particularly wellsuited for dissecting the requirements of various genetic pathways involved in exercise adaptation. Those findings can be of use in suggesting follow-up experiments to test conservation and efficacy in humans. The identification of $\mathrm{OA}$ as an exercise mimetic in Drosophila is an early example of how findings from invertebrate exercise models can suggest therapeutic possibilities in humans, such as using virtual reality to stimulate exercise-like metabolic effects.

\section{References}

1. Boström PA, Graham EL, Georgiadi A, et al. Impact of exercise on muscle and nonmuscle organs. IUBMB Life. 2013 Oct; 65(10): 845-50. doi: 10.1002/iub.1209. Review. PubMed PMID: 24078392.

2. Piazza N, Gosangi B, Devilla S, et al. Exercise-training in young Drosophila melanogaster reduces age-related decline in mobility and cardiac performance. PLoS One. 2009 Jun 11; 4(6): e5886. doi: 10.1371/journal.pone.0005886. PubMed PMID: 19517023; PubMed Central PMCID: PMC2691613.

3. Damschroder D, Cobb T, Sujkowski A, et al. Drosophila Endurance Training and Assessment of Its Effects on Systemic Adaptations. Bioprotocol. 2018; 8(19): e3037. DOI: 10.21769/BioProtoc.3037.

4. Sujkowski A, Saunders S, Tinkerhess M, et al. dFatp regulates nutrient distribution and long-term physiology in Drosophila. Aging Cell. 2012 Dec;11(6): 921-32. doi: 10.1111/j.1474-9726.2012.00864.x. Epub 2012 Aug 27. PubMed PMID: 22809097; PubMed Central PMCID: PMC3533766.

5. Laker RC, $\mathrm{Xu}$ P, Ryall KA, et al. A novel MitoTimer reporter gene for mitochondrial content, structure, stress, and damage in vivo. J Biol Chem. 2014 Apr 25; 289(17): 12005-15. doi: 10.1074/jbc. 
M113.530527. Epub 2014 Mar 18. PubMed PMID: 24644293; PubMed Central PMCID: PMC4002107.

6. Sujkowski A, Bazzell B, Carpenter K, et al. Endurance exercise and selective breeding for longevity extend Drosophila healthspan by overlapping mechanisms. Aging (Albany NY). 2015 Aug; 7(8): 535-52 PubMed PMID: 26298685; PubMed Central PMCID: PMC4586100.

7. Sujkowski A, Ramesh D, Brockmann A, et al. Octopamine Drives Endurance Exercise Adaptations in Drosophila. Cell Rep. 2017 Nov 14; 21(7): 1809-1823. doi: 10.1016/j.celrep.2017.10.065. PubMed PMID: 29141215; PubMed Central PMCID: PMC5693351.

8. Verlinden $\mathrm{H}$, Vleugels $\mathrm{R}$, Marchal E, et al. The role of octopamine in locusts and other arthropods. J Insect Physiol. 2010 Aug; 56(8): 85467. doi: 10.1016/j.jinsphys.2010.05.018. Epub 2010 Jun 3. Review. PubMed PMID: 20621695.

9. Roeder T. Octopamine in invertebrates. Prog Neurobiol. 1999 Dec; 59(5): 533-61. Review. PubMed PMID: 10515667.

10. Zouhal H, Jacob C, Delamarche P, et al. Catecholamines and the effects of exercise, training and gender. Sports Med. 2008; 38(5): 401-23. Review. PubMed PMID: 18416594.

11. Adamo SA, Linn CE, Hoy RR. The role of neurohormonal octopamine during 'fight or flight' behaviour in the field cricket Gryllus bimaculatus. J Exp Biol. 1995 Aug; 198(Pt 8): 1691-700. PubMed PMID: 7636443.

12. Crocker A, Shahidullah M, Levitan IB, et al. Identification of a neural circuit that underlies the effects of octopamine on sleep:wake behavior. Neuron. 2010 Mar 11; 65(5): 670-81. doi: 10.1016/j. neuron.2010.01.032. PubMed PMID: 20223202; PubMed Central PMCID: PMC2862355.

13. Crocker A, Sehgal A. Octopamine regulates sleep in drosophila through protein kinase A-dependent mechanisms. J Neurosci. 2008 Sep 17; 28(38): 9377-85. doi: 10.1523/JNEUROSCI.3072-08a.2008. PubMed PMID: 18799671; PubMed Central PMCID: PMC2742176.

14. Hoff $M$, Balfanz $S$, Ehling $P$, et al. A single amino acid residue controls Ca2+ signaling by an octopamine receptor from Drosophila melanogaster. FASEB J. 2011 Jul; 25(7): 2484-91. doi: 10.1096/fj.11180703. Epub 2011 Apr 8. PubMed PMID: 21478261; PubMed Central PMCID: PMC3114530.

15. Greiwe JS, Hickner RC, Shah SD, et al. Norepinephrine response to exercise at the same relative intensity before and after endurance exercise training. J Appl Physiol (1985). 1999 Feb; 86(2): 531-5. PubMed PMID: 9931187.

16. Davies CT, Few J, Foster KG, et al. Plasma catecholamine concentration during dynamic exercise involving different muscle groups. Eur J Appl Physiol Occup Physiol. 1974 Mar 28; 32(3): 195-206. PubMed PMID: 4836727.

17. Hartley LH, Mason JW, Hogan RP, et al. Multiple hormonal responses to graded exercise in relation to physical training. J Appl Physiol. 1972 Nov; 33(5): 602-6. PubMed PMID: 4635923.

18. Christensen NJ, Galbo H. Sympathetic nervous activity during exercise. Annu Rev Physiol. 1983; 45: 139-53. Review. PubMed PMID: 6342511.

19. Anderson RL, Wilmore JH, Joyner MJ, et al. Effects of cardioselective and nonselective beta-adrenergic blockade on the performance of highly trained runners. Am J Cardiol. 1985 Apr 26; 55(10): 149D-154D. PubMed PMID: 3993547.

20. Folgering H, van Bussel M. Maximal exercise power after a single dose of metoprolol and of slow-release metoprolol. Eur J Clin Pharmacol. 1980 Oct; 18(3): 225-9. PubMed PMID: 7439241.

21. Tesch PA. Exercise performance and beta-blockade. Sports Med. 1985 Nov-Dec; 2(6): 389-412. Review. PubMed PMID: 2866577.
22. Provencher S, Herve $P$, Jais $X$, et al. Deleterious effects of betablockers on exercise capacity and hemodynamics in patients with portopulmonary hypertension. Gastroenterology. 2006 Jan; 130(1): 120-6. PubMed PMID: 16401475.

23. Faghri PD, Glaser RM, Figoni SF. Functional electrical stimulation leg cycle ergometer exercise: training effects on cardiorespiratory responses of spinal cord injured subjects at rest and during submaximal exercise. Arch Phys Med Rehabil. 1992 Nov; 73(11): 1085-93. PubMed PMID: 1444777.

24. Doucet BM, Lam A, Griffin L. Neuromuscular electrical stimulation for skeletal muscle function. Yale J Biol Med. 2012 Jun; 85(2): 20115. Epub 2012 Jun 25. Review. PubMed PMID: 22737049; PubMed Central PMCID: PMC3375668.

25. Lau RW, Liao LR, Yu F, et al. The effects of whole body vibration therapy on bone mineral density and leg muscle strength in older adults: a systematic review and meta-analysis. Clin Rehabil. 2011 Nov; 25(11): 975-88. doi: 10.1177/0269215511405078. Epub 2011 Aug 17. Review. PubMed PMID: 21849376.

26. Gilsanz V, Wren TA, Sanchez M, et al. Low-level, high-frequency mechanical signals enhance musculoskeletal development of young women with low BMD. J Bone Miner Res. 2006 Sep; 21(9): 1464-74. PubMed PMID: 16939405.

27. Schoenfeld BJ. The mechanisms of muscle hypertrophy and their application to resistance training. J Strength Cond Res. 2010 Oct; 24(10): 2857-72. doi: 10.1519/JSC.0b013e3181e840f3. Review. PubMed PMID: 20847704.

28. Baar K, Nader G, Bodine S. Resistance exercise, muscle loading/ unloading and the control of muscle mass. Essays Biochem. 2006; 42: 61-74. Review. PubMed PMID: 17144880.

29. Goldberg AL, Etlinger JD, Goldspink DF, et al. Mechanism of workinduced hypertrophy of skeletal muscle. Med Sci Sports. 1975 Fall; 7(3): 185-98. PubMed PMID: 128681.

30. Björntorp P. Do stress reactions cause abdominal obesity and comorbidities. Obes Rev. 2001 May; 2(2): 73-86. PubMed PMID: 12119665.

31. Salmon P. Effects of physical exercise on anxiety, depression, and sensitivity to stress: a unifying theory. Clin Psychol Rev. 2001 Feb; 21(1): 33-61. Review. PubMed PMID: 11148895.

32. McEwen BS. Protective and damaging effects of stress mediators. $\mathrm{N}$ Engl J Med. 1998 Jan 15; 338(3): 171-9. Review. PubMed PMID: 9428819.

33. Tsatsoulis A, Fountoulakis S. The protective role of exercise on stress system dysregulation and comorbidities. Ann N Y Acad Sci. 2006 Nov; 1083: 196-213. Review. PubMed PMID: 17148741.

34. Yanagibori R, Suzuki Y, Kawakubo K, et al. Carbohydrate and lipid metabolism after 20 days of bed rest. Acta Physiol Scand Suppl. 1994; 616: 51-7. PubMed PMID: 8042526.

35. Coker RH, Hays NP, Williams RH, et al. Bed rest worsens impairments in fat and glucose metabolism in older, overweight adults. J Gerontol A Biol Sci Med Sci. 2014 Mar; 69(3): 363-70. doi: 10.1093/gerona/ glt100. Epub 2013 Jul 31. PubMed PMID: 23902932; PubMed Central PMCID: PMC3976140.

36. Dirks ML, Wall BT, van de Valk B, et al. One Week of Bed Rest Leads to Substantial Muscle Atrophy and Induces Whole-Body Insulin Resistance in the Absence of Skeletal Muscle Lipid Accumulation. Diabetes. 2016 Oct; 65(10): 2862-75. doi: 10.2337/ db15-1661. Epub 2016 Jun 29. PubMed PMID: 27358494.

37. Laranjeiro R, Harinath G, Burke D, et al. Single swim sessions in C. elegans induce key features of mammalian exercise. BMC Biol. 2017 Apr 10; 15(1): 30. doi: 10.1186/s12915-017-0368-4. PubMed PMID: 28395669; PubMed Central PMCID: PMC5385602. 